\title{
Surgical Resection of a Rare Inflammatory Fibroid Polyp of the Stomach: A Case Review
}

\author{
Jessica L. Buicko ${ }^{\mathrm{a}, \mathrm{e}}$, Elias Fakhoury ${ }^{\mathrm{b}}$, Michael A. Lopez ${ }^{\mathrm{c}}$, Miguel A. Lopez-Viego ${ }^{\mathrm{d}}$
}

\begin{abstract}
Inflammatory Fibroid Polyps are uncommon sessile or pedunculated polyploid masses that have been estimated to account for roughly one percent of all gastric polyps. They have been reported throughout the gastrointestinal tract in locations including the stomach, small bowel, colon, and esophagus. We present a rare case of an inflammatory fibroid polyp of the gastric antrum in a 57 yearold patient presenting with occult anemia, which was successfully treated with surgical resection. The diagnosis of an inflammatory fibroid polyp is a difficult one, as clinical presentation is usually non-specific and endoscopy with biopsy specimens may not be sufficient to allow for a histological diagnosis. Diagnosis is best established with immunohistochemistry of the excised tumor. Inflammatory fibroid polyps are positive for CD34, PDGFR-alpha, and vimentin, and are negative for CD-117, and S-100, among others. Once diagnosed, the definitive treatment for inflammatory fibroid polyps is excision. The anatomic location and size of the polyp determine whether the procedure is open or endoscopic. Inflammatory fibroid polyps have not been found to recur after excision, nor have additional polyps been found to develop.
\end{abstract}

Manuscript accepted for publication April 19, 2012

${ }^{a}$ University of Miami Miller School of Medicine, Miami, FL, USA

${ }^{b}$ NOVA Southeastern University College of Osteopathic Medicine, USA

${ }^{\mathrm{c} C}$ Cornell University, BS Biology, USA

${ }^{\mathrm{d} D e p a r t m e n t ~ o f ~ G e n e r a l ~ a n d ~ V a s c u l a r ~ S u r g e r y, ~ J F K ~ M e d i c a l ~ C e n t e r, ~}$ Atlantis, FL and Bethesda Memorial Hospital, Boynton Beach, FL, USA

${ }^{\mathrm{e}}$ Corresponding author: Jessica L. Buicko.

Email: Jbuicko@med.miami.edu

doi: $10.4021 / \mathrm{jcs} 49 \mathrm{w}$
Keywords: Inflammatory fibroid polyp; Resection; Stomach

\section{Introduction}

Inflammatory fibroid polyps are uncommon sessile or pedunculated polyploid masses that have been documented to occur throughout the gastrointestinal tract [1]. Vanek first described these lesions in 1949 as "gastric submucosal granulomas with eosinophilic infiltration" after reporting six cases of lesions that consisted of loosely arranged collagenous tissue with fibroblasts, blood and lymph capillaries, and eosinophilic polymorphonuclear leukocytes [2]. In 1953, Helwig and Ranier, proposed the name "Inflammatory Fibroid Polyp," which has now become the universally accepted term [3]. We present a rare case of an inflammatory fibroid polyp of the gastric antrum in a 57 year-old patient presenting with occult anemia, which was successfully treated with surgical resection.

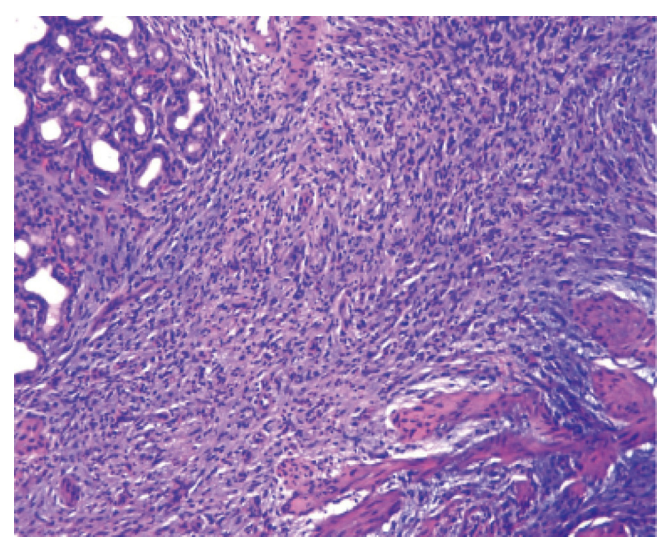

Figure 1. H and E Stain. Microscopically, the lesion has a granulation tissue appearance with spindle cell proliferation, prominent vasculature, and inflammatory cells including significant eosinophils. It infiltrates mucosal glandular tissue with trapped glands. The surface is ulcerated with acute inflammation. 


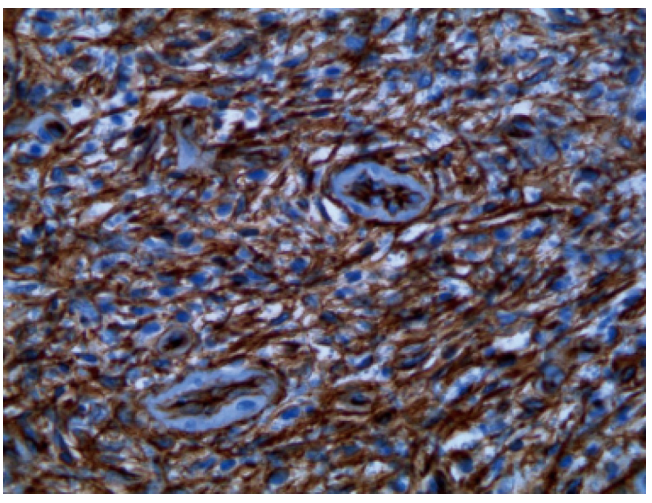

Figure 2. Diffuse reactivity of CD34 staining

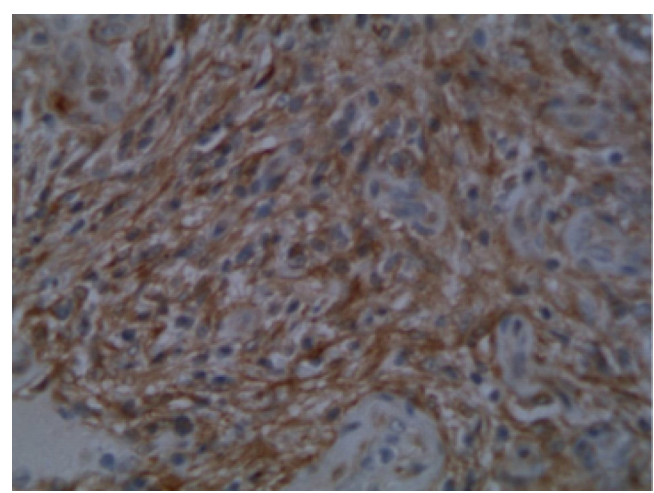

Figure 3. Diffuse reactivity of PDGFR Alpha staining

\section{Case Report}

A 57 year-old man presented to our teaching service with a history of occult anemia. He underwent upper endoscopy and was found to have a large prepyloric ulcerative mass with evidence of active bleeding. Subsequent biopsies of the mass revealed normal mucosa. $H$. Pylori testing was negative.

The surgical team proceeded with exploratory laparotomy and ultimately performed a gastrectomy with excision of the mass, antrectomy, and Billroth II gastrojejunostomy reconstruction. Intraoperative frozen section analysis was suggestive of a spindle cell neoplasm. Additional proximal prepyloric and distal duodenal margins were negative for tumor.

Further pathology studies revealed a $2.6 \mathrm{~cm}$ spindle cell neoplasm. Based on gross appearance, histology, and an immunoprofile of CD117-, DOG1-, CD34+, and PDGFR Alpha + , the tumor was classified as an inflammatory fibroid polyp (Fig. 1-3).

Post-operatively, the patient remained stable. His diet was increased gradually and he was discharged home one week later.

\section{Discussion}

Inflammatory fibroid polyps account for between 1 to $3 \%$ of gastric polyps [4-6]. They have been reported throughout the gastrointestinal tract in locations including the stomach, small bowel, colon, and esophagus [6]. Approximately 70\% of inflammatory fibroid polyps are located in the gastric antrum and $20 \%$ in the small bowel.

There is much debate over the etiology and pathophysiology of these lesions. There have been reported associations with chronic atrophic gastritis, but often times the adjacent mucosa is normal [4]. It has been suggested by Nishiyama et al, that there is a relationship between H. Pylori and the development and treatment of inflammatory fibroid polyps [7]. No conclusions have been made as other cases, including the one presented above, have not shown an association with H. pylori [8]. An English report suggests there may be a familial link as a family in Devon, UK has had females in three succeeding generations develop multiple inflammatory fibroid polyps [9]. There has been no other evidence thus far of a possible genetic link. In addition, it has been hypothesized that there is an allergic element to the development of these lesions due to their eosinophilic nature, yet this has not been widely accepted, as there is no accompanying peripheral eosinophilia $[6,10]$. In their recent analysis of the current literature, Mucientes et al found that dendritic, neural, fibroblastic, myofibroblastic, histiocytic, and vascular cells have all been suggested by various authors as cell types to originate inflammatory fibroid polyps [11]. Therefore, no significant conclusions can be made at this juncture.

From a clinical standpoint, inflammatory fibroid polyps may be found incidentally or when substantial enough in size, may mimic signs and symptoms of gastric cancer. Patients may complain of non-specific abdominal or epigastric pain, nausea, vomiting, or melena, secondary to gastrointestinal bleeding from ulceration $[10,12]$. In their 1-year national study of 120,000 patients with gastric polyps, Carmack et al found that the median age at diagnosis was 61 years and the most common presenting symptoms were dyspepsia $(37.5 \%)$, anemia $(25 \%)$, and gastroesophageal reflux $(14.3 \%)$ [13].

Accordingly, endoscopy with ensuing biopsies is often the first diagnostic modality used in these patients [10]. Macroscopically, inflammatory fibroid polyps are usually solitary submucosal lesions that are approximately $1.5 \mathrm{~cm}$ in size on average [6]. Biopsy specimens may not be sufficient to allow for a histological diagnosis [14]. Definitive diagnosis is best established with immunohistochemistry of the excised tumor [6]. Inflammatory fibroid polyps are positive for CD34, PDGFR-alpha, and vimentin, and are negative for CD-117, and S-100, among others $[1,6,11,15]$.

The differential diagnosis for inflammatory fibroid polyps includes gastrointestinal stromal tumors (GIST), eosinophilic gastroenteritis, inflammatory myofibroblastic tumors, and benign mesenchymal tumors such as neurofibromas 
and schwannomas $[6,11]$. Inflammatory fibroid polyps are similar to GIST tumors as they both demonstrate spindle cell proliferation and are CD34 positive. They differ in that GIST tumors do not demonstrate increased eosinophils and are DOG1 and CD-117 positive [6]. Eosinophilic gastritis is found in patients with strong histories of allergies and often has a transmural infiltrate. Neurofibromas and schwannomas both are spindle-shaped but lack the immunohistochemical profile consistent with an inflammatory fibroid polyp as they are negative for CD34 and positive for S-100 [11]. Inflammatory myofibroblastic tumors occur less frequently in the stomach than the remainder of the gastrointestinal tract, but often present with similar clinical manifestations. These tumors have a similar inflammatory histological component yet do not have the eosinophilic infiltrate, nor vascular proliferation. They also have a tendency to recur [16].

Once diagnosed, the definitive treatment for inflammatory fibroid polyps is excision. The anatomic location and size of the polyp determine whether the procedure is open or endoscopic [17]. Inflammatory fibroid polyps have not been found to recur after excision, nor have additional polyps been found to develop [18].

\section{Special Thanks}

Dr. Wayne Cai, Pathologist at JFK Medical Center.

\section{References}

1. Santos Gda C, Alves VA, Wakamatsu A, Zucoloto S. Inflammatory fibroid polyp: an immunohistochemical study. Arq Gastroenterol. 2004;41(2):104-107.

2. Vanek J. Gastric submucosal granuloma with eosinophilic infiltration. Am J Pathol. 1949;25(3):397-411.

3. Helwig EB, Ranier A. Inflammatory fibroid polyps of the stomach. Surg Gynecol Obstet. 1953;96(3):335-367.

4. Carmack SW, Genta RM, Graham DY, Lauwers GY. Management of gastric polyps: a pathology-based guide for gastroenterologists. Nat Rev Gastroenterol Hepatol. 2009;6(6):331-341.

5. Woodward K, Gangarosa LM, Hunt HV. Gastric inflammatory fibroid polyp. Indian J Pathol Microbiol. 2011;54(3):622-623.

6. Morales-Fuentes GA, de Arino-Suarez M, Zarate-Osorno A, Rodriguez-Jerkov J, Terrazas-Espitia F, Per-
ez-Manauta J. Vanek's polyp or inflammatory fibroid polyp. Case report and review of the literature. Cir Cir. 2011;79(3):242-245, 263-247.

7. Nishiyama Y, Koyama S, Andoh A, Kishi Y, Yoshikawa $\mathrm{K}$, Ishizuka I, Yokono T, et al. Gastric inflammatory fibroid polyp treated with Helicobacter pylori eradication therapy. Intern Med. 2003;42(3):263-267.

8. Hattori Y, Kobayashi S, Takahashi H, Yoneda M, Inamori M, Abe Y, Kubota K, et al. Gastric inflammatory fibroid polyp treated by endoscopic submucosal dissection. Case Rep Gastroenterol. 2008;2(2):283-286.

9. Allibone RO, Nanson JK, Anthony PP. Multiple and recurrent inflammatory fibroid polyps in a Devon family ('Devon polyposis syndrome'): an update. Gut. 1992;33(7):1004-1005.

10. Dominguez-Ferreras, Esther, et al. "Large inflammatory fibroid polyp of the stomach." European Journal of Radiology. vol. 55, pp.55-59, 2005.

11. Mucientes P, Mucientes F, Klaassen R. Inflammatory fibroid polyp associated with early gastric carcinoma: a case report. Ann Diagn Pathol. 2012;16(2):148-151.

12. Saritas U, Ustundag Y, Gedikoglu G. Successful endoscopic treatment of huge gastric inflammatory fibroid polyp. Turk J Gastroenterol. 2011;22(2):224-226.

13. Carmack SW, Genta RM, Schuler CM, Saboorian MH. The current spectrum of gastric polyps: a 1-year national study of over 120,000 patients. Am J Gastroenterol. 2009;104(6):1524-1532.

14. Zinkiewicz K, Zgodzinski W, Dabrowski A, Szumilo J, Cwik G, Wallner G. Recurrent inflammatory fibroid polyp of cardia: a case report. World J Gastroenterol. 2004;10(5):767-768.

15. Daum O, Hatlova J, Mandys V, Grossmann P, Mukensnabl P, Benes Z, Michal M. Comparison of morphological, immunohistochemical, and molecular genetic features of inflammatory fibroid polyps (Vanek's tumors). Virchows Arch. 2010;456(5):491-497.

16. Makhlouf HR, Sobin LH. Inflammatory myofibroblastic tumors (inflammatory pseudotumors) of the gastrointestinal tract: how closely are they related to inflammatory fibroid polyps? Hum Pathol. 2002;33(3):307-315.

17. Godey SK, Diggory RT. Inflammatory fibroid polyp of the oesophagus. World J Surg Oncol. 2005;3:30.

18. Paikos D, Moschos J, Tzilves D, Koulaouzidis A, Kouklakis G, Patakiouta F, Kontodimou K, et al. Inflammatory fibroid polyp or Vanek's tumour. Dig Surg. 2007;24(3):231-233. 